Reseña

\section{Elena Catalán, Gabriel Jover y Enrique Llopis (eds.). El delme com a font per a la història rural. Girona, Associació d'Història Rural de les Comarques Gironines, 2020, 276 pp. ISBN: 978-8499845401.}

Este libro reúne una compilación de trabajos fruto de una Jornada sobre El diezmo como fuente para la historia rural (Girona, Centre d'Estudis d'Història Rural, 26 de octubre de 2018). Su denominador común es la reflexión crítica en torno a la idoneidad de la fuente para estimar la evolución del producto agrario durante la Edad Moderna. Una finalidad que estuvo en la base de numerosos trabajos promovidos entre 1960-1970 por algunos miembros destacados de la Escuela de los Annales. Esta línea de investigación se abandonó, no obstante, por la dificultad de establecer comparaciones. De ahí la pertinencia de la primera contribución a cargo de Llopis y Sebastián Amarilla, en la que se enumeran, precisamente, los principales fines para los que resultan aptos los registros decimales. Reflexionan sobre su idoneidad para estimar el crecimiento agrario preindustrial y esgrimen las posibles ventajas e inconvenientes respecto a otras fuentes y metodologías. Apoyan sus argumentaciones en la sistematización de las «averiguaciones de veros valores» para el pago del subsidio y el excusado de distintas diócesis castellanas cuyos resultados, dada la larga trayectoria investigadora de ambos autores, pueden contrastar con la tendencia reflejada en otras fuentes. A pesar de su árido ejercicio cuantitativo y, por supuesto, archivístico y documental, subrayan la imposibilidad de "medir lo invisible». Esgrimen, así mismo, fundamentadas razones sobre la pertinencia de corregir al alza las estimaciones del PIB y del PIB per cápita recogidas en los trabajos auspiciados por Maddison. Y, en particular, por otras aportaciones recientes que han recurrido a la denominada vía de la demanda sirviéndose, exclusivamente, de las series sobre precios y salarios de los siglos XVI-xvIII de varias ciudades europeas. Una metodología que ponen en entredicho por la evidencia incontestable de que en la época preindustrial las rentas salariales no constituían la principal fuente de ingresos de las comunidades rurales.

En el segundo trabajo, Catalán propone utilizar el diezmo para conocer cómo se distribuía el tributo dentro del estamento eclesiástico. En particular, para tratar de cuantificar la desigualdad económica dentro del colectivo menos favorecido: el clero parroquial. La recaudación se destinaba, con una proporción muy desigual, a remunerar (a beneficiar siguiendo la terminología de la época) a todos los servidores de la Iglesia: desde la más alta dignidad eclesiástica al párroco de la aldea más modesta. Tal y como se presenta el trabajo, resulta de lectura obligada para los investigadores poco fami- liarizados con la variedad de las series decimales. Se insiste en que la mayoría de los registros reflejan solo la porción percibida por algún beneficiado. La autora se detiene, asimismo, en explicar las diferencias de significado de algunos términos concretos; en función, sobre todo, de los distintos ámbitos geográficos.

Los siguientes capítulos se refieren a distintos territorios de la Corona de Aragón. Se profundiza en algunas de sus peculiaridades y en la evolución de determinadas magnitudes. La contribución de Mallorquí analiza la recaudación y el reparto del diezmo durante los siglos xiII y xIv en un territorio de la denominada Catalunya Vella: el obispado de Girona. Resulta doblemente interesante por la cronología que abarca y las especiales prerrogativas del perceptor de dichas rentas. El autor dedica una especial atención a explicar el origen de la dependencia de los señores laicos respecto al obispo y a reseñar las principales fuentes en las que fundamenta su investigación. Profundiza en las distintas formas de diezmar y en la variada tipología de productos sujetos a imposición. Las distintas jerarquías establecidas en torno al diezmo son complejas, por lo que acompaña el texto de croquis, cuadros y mapas que facilitan su comprensión. Se detiene, igualmente, en cuestiones terminológicas e insiste, acertadamente, en que el diezmo no fue un tributo exclusivamente eclesiástico. Desde la Edad Media hasta su abolición definitiva, la adscripción social de sus perceptores fue muy diversa, mientras que el peso del tributo recayó, esencialmente, en las comunidades campesinas.

En un capítulo posterior, Gifre se ocupa del mismo espacio geográfico. Analiza el valor de los arrendamientos de las capellanías de la catedral de Girona entre 1503-1705. Argumenta por qué no puede considerarse representativo de la evolución del producto agrario, sintetiza la bibliografía específica sobre la renta señorial y describe las fuentes y la metodología utilizada. Presenta una serie deflactada sobre la variable objeto de estudio y una propuesta de periodización. Se interroga, asimismo, sobre las razones que pudieron motivar las principales oscilaciones y constata, para algunas parroquias, la correlación entre la evolución de la renta y las series de bautismos. La serie no representa, sin embargo, la evolución del producto agrario, sino una parte los ingresos señoriales de una institución concreta. En particular, las rentas mayores procedentes de las fundaciones establecidas por particulares a favor de la catedral que el cabildo cede en arrendamiento para sufragar el mantenimiento de los clérigos.

El estudio sobre Valencia está a cargo de Torró, quien a partir del material recopilado por Ardit y de la sistematización de otras fuentes, presenta distintos indicadores que, desde una perspectiva agregada, considera indicativos de la evolución del producto agrario entre los siglos xvI-XVIII. Advierte, asimismo, que la propia naturaleza de las fuentes decimales permite tomarlas solo como un reflejo de la tendencia general. Por ello, 
sugiere multiplicar esfuerzos a escala local y presenta, a modo de ejemplo, un estudio focalizado en la comarca de Alcoi (1440-1830) a partir de las rentas en especie de la tercia episcopal. Se centra en el comportamiento de algunos productos concretos: cereales, vino y aceite. Sin embargo, interesa no perder de vista que fundamenta sus conclusiones en las rentas de un único perceptor.

El volumen se cierra con el análisis de Jover sobre la parte decimal que en Mallorca gravaba las cosechas de aceitunas correspondientes al cabildo catedralicio. La especificidad del tema se justifica tanto por la especialización oleícola de la isla como por el interés de disponer de series sobre producción y precios del principal producto de exportación. Unas series que se han elaborado, muchas veces, sin tener en cuenta las limitaciones documentales, la parte de la producción que reflejan o la disparidad de precios en función del destino final del aceite. De ahí el doble interés de este ejercicio: la crítica a los escrutinios (manifests de trullades) y la reconstrucción de la evolución del precio del aceite en el mercado de Palma a partir de contabilidades conventuales. Sin embargo, el resultado no es alentador por lo que respecta a la utilización del diezmo como indicador de la producción, mientras que los escrutinios sí pueden servir para explorar la desigual distribución de la renta en el sector oleícola.

Los distintos trabajos muestran, en síntesis, que las evaluaciones sobre producción que acompañan la gestión del diezmo pueden considerarse válidas -siempre con las precauciones señaladas- para reconstruir la evolución y composición del producto agrario. Sin embargo, las dudas sobre su fiabilidad se acentúan cuando el tributo es objeto de arrendamiento; especialmente cuando en su tramo final se convierte en una tasa de sustracción en disputa, pues se ha podido constatar que su erosión minaba su fuerza como punción feudal y su credibilidad como indicador del producto agrario.

Antònia Morey Tous Universitat de les Illes Balears 